\title{
BLICKDIAGNOSE
}

Stellen Sie uns

Ihren Fall vor.

Bei Veröffentlichung erhalten Sie 100 Euro!

cornelius.heyer@ springer.com

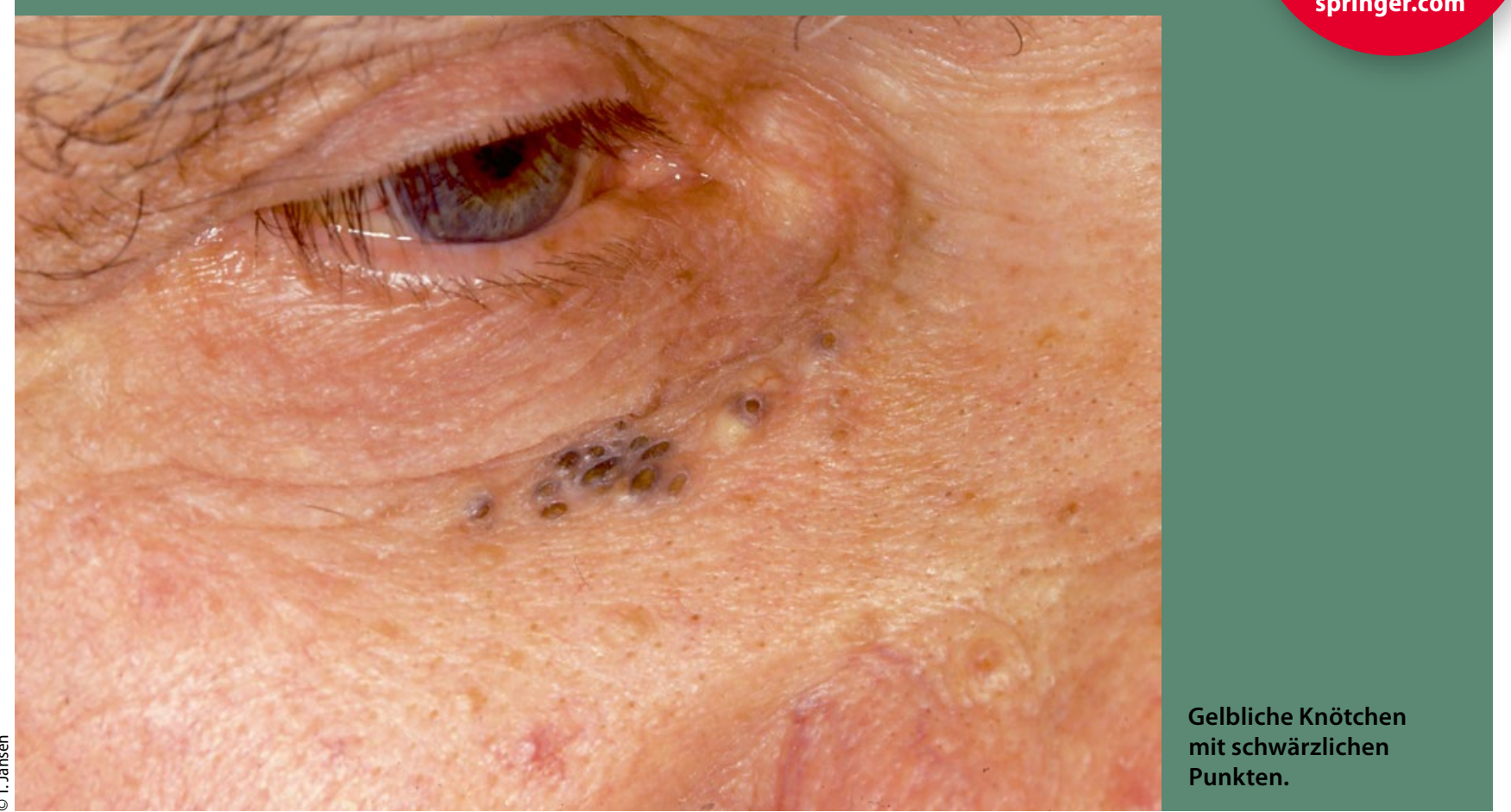

\section{Gelb-schwarze Knötchen}

\section{Da vergeht die Freude an der Sonnenbräune}

_ Bei einem 56-jährigen hellhäutigen Patienten (Hauttyp I nach der Fitzpatrick-Klassifikation), der sich über Jahrzehnte intensiv der Sonne aussetzte, bestanden seit etwa sechs Jahren symptomlose Hautveränderungen im Bereich des rechten Nasen-Augen-Winkels. In den letzten Jahren war keine Zunahme der Effloreszenzen an Zahl und Größe festzustellen. In der Familie bestanden keine vergleichbaren Hautveränderungen. Bei der klinischen Untersuchung fanden sich gruppiert stehende, gelbliche Knötchen unterschiedlicher Größe mit zentral sitzenden schwärzlichen Punkten. Die Haut in der Umgebung war schlaff, runzlig und gering gelblich verfärbt.

Die Diagnose lautete Morbus Favre-Racouchot. Das relativ häufige Krankheitsbild wurde erstmals 1931 vom französichen Dermatologen Maurice Favre und 1937 von seinem Schüler Jean Racouchot beschrieben. Diese auch aktinische oder - wenig schmeichelhaft - senile (Alters-)Komedonen genannten Hautveränderungen finden sich im Gesicht älterer, hellhäutiger Menschen, wobei vorzugsweise das männliche Geschlecht befallen zu sein scheint. Die Effloreszenzen sind meist symmetrisch verteilt. Ein einseitiger Befall wie im vorliegenden Fall ist hingegen selten. Die oberen Wangen, die Periorbital- und die Temporalregion weisen meist gruppiert stehende, offene und geschlossene Komedonen ohne Entzündungszeichen auf. Diese können solche Ausmaße annehmen, dass sie wie Zysten in der gelblich verfärbten, verdickten, elastotisch veränderten Haut liegen.

Der Morbus Favre-Racouchot gehört zu den zahlreichen pathologischen Veränderungen, die durch exzessive Sonnenexposition hervorgerufen werden. Die Komedonen entstehen durch eine UV-bedingte Metaplasie des Follikelepithels und stellen keine Form der Akne dar. Es gibt Hinweise darauf, dass Rauchen zur Entstehung beitragen kann. Geeignete Therapievorschläge sind in der Literatur kaum zu finden. Die lokale Applikation von Retinoiden, insbesondere Vitamin-A-Säure (Tretinoin), allein oder in Kombination mit manueller Entfernung der Komedonen war in manchen Fällen erfolgreich.

\footnotetext{
$\rightarrow$ PD Dr. med. habil. Thomas Jansen

Höntroper Strasse 102, 44869 Bochum
} 